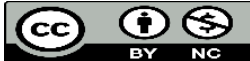

\title{
AUTORRECONHECIMENTO E RECONHECIMENTO SOCIAL DE GÊNERO COMO DISPOSITIVOS DE SUBJETIVAÇÃO E ACESSO ÀS MEDIDAS PROTETIVAS DA LEI № 11.340/2006
}

SELF-RECOGNITION AND SOCIAL RECOGNITION OF GENDER AS SUBJECTIFICATION DEVICES AND ACCESS TO THE PROTECTIVE MEASURES REGULATED BY THE BRAZILIAN LAW NUMBER $11.340 / 2006$

Bárbara Amelize Costa

Adalberto Antonio Batista Arcelo

\section{RESUMO}

Este artigo propõe, a partir dos conceitos foucaultianos de dispositivos de subjetivação e de insurreição dos saberes sujeitados, uma análise de viabilidade constitucional e penal para que as mulheres transexuais e as travestis tenham acesso às medidas protetivas previstas na Lei Maria da Penha. Aspectos identitários de autorreconhecimento e reconhecimento social devem ser levados em consideração quando se determina o que é ser (tornar-se) mulher e, nestes termos, as medidas protetivas determinadas na Lei devem ser acessíveis às sujeitas que vivenciam papéis de gênero feminino.

Palavras-chave: Autorreconhecimento. Gênero. Mulher transexual. Travesti. Lei № 11.340/2006. 


\section{ABSTRACT}

Based on Foucault's concepts of subjectification devices and insurrection of subjugated knowledges, this article proposes an analysis of certain constitutional and penal feasibilities in order to allow transsexual women and transvestites to have access to the protective measures provided by the Brazilian Law popularly known as Lei Maria da Penha. Identity aspects of self-recognition and social recognition must be taken into account when determining the legal meaning of what it is to be (or to become) a woman. In these terms, this article proposes that the protective measures determined by Maria da Penha Law must also be accessible to subjects who experience feminine roles.

Keywords: Gender. Self-recognition. Transsexual woman. Transvestite. Law n. $11.340 / 2006$.

\section{INTRODUÇÃO}

Analisa-se, neste artigo, a Lei № 11.340, de 7 de agosto de 2006 (BRASIL, 2006) e os papéis de gênero na sociedade brasileira contemporânea. De antemão, faz-se necessário delimitar que esta análise parte da compreensão de duas premissas básicas: a constitucionalidade da referida Lei e sua aplicabilidade às relações homoafetivas entre mulheres.

Com a primeira premissa, busca-se aplicar um filtro hermenêutico-constitucional para a problematização do princípio da igualdade. Tratar os iguais de forma igual e os diferentes de forma diferente, na medida em que se diferenciam, é elementar para determinar o que significa igualdade em Direito. Em relação à segunda premissa, as condutas previstas na Lei encontram-se em homens e mulheres que praticam atos de violência doméstica e familiar contra mulheres. Revela-se o potencial emancipatório da Lei que, por tal perspectiva, atua como dispositivo de subjetivação em prol da afirmação identitária - autorreconhecimento e reconhecimento social - de subjetividades individuais e coletivas historicamente marginalizadas e excluídas da sociedade brasileira.

É necessário frisar que o rigor com que a Lei no 11.340/2006 (BRASIL, 2006) trata a sujeição passiva para proteger quem historicamente foi oprimido é a força motriz de sua existência. Isto é, a Lei Maria da Penha 
não visa - e nem deveria - proteger o hipossuficiente, mas um sujeito passivo específico: a mulher. Nestes termos, o reconhecimento de quaisquer outras elementares determinantes da sujeição passiva das condutas previstas na Lei poderiam suscitar, numa primeira análise, a ocorrência de flexibilização do bem jurídico tutelado pela Lei - o que ocasionaria uma ofensa à tipicidade e ao princípio constitucional da legalidade estrita.

Todavia, saliente-se, a definição do que é ser mulher não advém de nenhum contexto normativo e, nestes termos, abrange a mulher transexual e a travesti. Os critérios meramente biológicos que consubstanciam que, mesmo existindo a cirurgia de transgenitalização ${ }^{1}$, órgãos internos não são modificados mantendo uma estruturação do sexo oposto ao de transformação, aquiescem em desconsiderar, no caso da mulher transexual, aspectos psicológicos que também são resultantes da opressão historicamente sofrida pela mulher.

Os critérios que consubstanciam que, não existindo a cirurgia de transgenitalização, nem uso do nome social ${ }^{2}$ nas mulheres transexuais e nas travestis, tratar-se-ia de um homem e, portanto, de um elemento estranho à sujeição passiva das medidas protetivas da Lei Maria da Penha, desconsideram a construção identitária de autorreconhecimento e os aspectos psicoculturais que também culminam na mesma resultante histórica.

O que se defende neste trabalho é que, independentemente de quaisquer alterações físicas ou morfológicas - traduzidas na cirurgia de transgenitalização - ou do uso civil do nome social, a pessoa que se autorreconhece mulher e a que socialmente assim é reconhecida tenha acesso às medidas protetivas da Lei, tendo como filtro hermenêutico a força normativa dos princípios constitucionais e seu impacto em toda a dinâmica jurídica do Brasil contemporâneo.

Os conceitos foucaultianos de dispositivos de subjetivação e de insurreição dos saberes sujeitados são relevantes, neste trabalho, porque o primeiro demonstra a relação entre fazeres e saberes que forjam verdades e subjetividades, trazendo uma pretensa verdade sobre determinadas identidades que, assim, se tornam estigmatizadas. 0 segundo - insurreição dos saberes sujeitados - traz um consistente suporte para uma inversão de um certo poder-saber historicamente construído, que tem a função de marginalização e de exclusão. Assim, a partir dessa subversão 
de um poder-saber hegemônico, no caso materializado na fragilização do sexo não comum, seria possível considerar o empoderamento de grupos identitários historicamente subjugados pelo próprio Direito.

\section{MULHER: O ETERNO TORNAR-SE}

A feminilidade e suas significantes não são caraterísticas impressas na anatomia, mas, antes, um processo de socialização que envolve nuances e vivências culturais e psicológicas, conforme aduz Heleieth Saffioti (2013):

A mulher universal tanto quanto o homem universal são criações mentais inexistentes no terreno factual. Existem, isto sim, seres humanos condicionados pela situação histórico-social em que vivem, neste contexto, e só neste, devem ser observados e explicados (SAFFIOTI, 2013, p. 411).

A determinação do conceito de mulher não é e nem poderia ser normativo - já que seria exclusivo quando confrontado com a outra pessoa ou o outro grupo social. A mulher é uma construção social, conforme aduz Simone de Beauvoir (1967):

Ninguém nasce mulher: torna-se mulher. Nenhum destino biológico, psíquico, económico, define a forma que a fêmea humana assume no seio da sociedade; é o conjunto da civilização que elabora esse produto intermediário entre o macho e o castrado que qualificam de feminino. Somente a mediação de outrem pode constituir um indivíduo como um outro (BEAUVOIR, 1967, p. 9).

A definição normativa do que se é mulher revela uma cultura patriarcal de dominação pela alteridade - onde o outro é dado pela negação (ao ser confrontado com o que é definido) e, consequentemente, é inferiorizado.

Critérios físicos ou morfológicos aquiescem em desconsiderar que os aspectos psicológicos da natureza e cultura humanas não são estáticos na esfera social. A simplificação legal de conceitos sociais que abarcam necessárias imersões no aspecto psicológico da natureza e da condição humanas contrariam principiologias de Direitos Humanos, além de 
revelarem tecnologias de poder advindas do controle da população por meio do uso da gestão da sexualidade (biopoder).

A ciência penal é uma atividade produtora de esclarecimentos, que tem o condão de racionalizar as teorias de forma a tornar os pensamentos abstratos que a sustentam devidamente falseáveis com fulcro no afastamento da subjetividade do saber. Desconsiderar que o conceito de mulher se vincula a uma construção identitária e esta, por sua vez, a aspectos psicológicos de autorreconhecimento e reconhecimento social, é aceitar unicamente um discurso de autoridade que esvazia a cientificidade e dogmatiza a ciência, desconsiderando as nuances sociais de identificação humana.

0 parâmetro tradicional de identificação da mulher, marcado pelo sexo feminino, pela vagina ou pela morfologia feminina, não é recepcionado nestas reflexões, posto que tal parâmetro se alicerça em elementos coloniais e subalternizantes como os conceitos de anatomia, de patriarcalismo e de heteronormatividade. Nestes termos, segundo Odon Maranhão (1995):

Não se pode mais considerar o conceito de sexo fora de uma apreciação plurivetorial. Em outros termos, o sexo é a resultante de um equilíbrio de diferentes fatores que agem de forma concorrente nos planos físico, psicológico e social. Assim, fatores genéticos, endócrinos, somáticos, psicológicos e sociais se integram para definir a situação de uma pessoa em termos sexuais. As implicações jurídicas serão decorrentes dessa integração (MARANHÃO, 1995, p. 127)

As transgêneras ${ }^{3}$ que são reconhecidas socialmente, reconhecem-se internamente ou vivenciam papéis da feminilidade devem ser encaradas como são: mulheres (com todas as necessárias imprecisões e constantes construções do referido termo). A mulher transexual, as intersex femininas e as travestis vivenciam papéis e expressões de gênero que as tornam o que, de fato, já são psicologicamente.

Neste sentido, considera-se que o autorreconhecimento de gênero (determinação do sujeito perante si próprio) e reconhecimento social (determinação do sujeito perante outros) sejam considerados suficien- 
tes para a detecção da sujeição passiva nas condutas protegidas pela Lei Maria da Penha e para acesso às medidas protetivas da referida Lei.

\section{O PATRIARCALISMO E O CONTROLE SOCIAL}

Em consonância às teorias feministas e à própria motivação da construção da Lei Maria da Penha, tem-se como fato as desigualdades históricas entre homens e mulheres.

A desigualdade entre homens e mulheres é um traço presente na maioria das sociedades, se não em todas. Na maior parte da história, esta desigualdade não foi camuflada nem escamoteada; pelo contrário, foi assumida como um reflexo da natureza diferenciada dos dois sexos e necessária para a sobrevivência e progresso da espécie. Ao recusar esta compreensão, ao denunciar a situação das mulheres como efeito de padrões de opressão, o pensamento feminista caminhou para uma crítica ampla do mundo social, que reproduz assimetrias e impede a ação autônoma de muitos de seus integrantes. Por isso, na teoria política produzida nas últimas décadas, a contribuição do feminismo se mostrou crucial (MIGUEL, 2014, p. 17).

Se, por um lado, os movimentos feministas - frutos de uma reatividade histórica a uma dominação patriarcal - denunciaram as relações de poder e promoveram o resgate de diversos direitos, como o exercício da cidadania e o acesso ao conhecimento, tem-se, por outro, ainda nos dias atuais, a objetificação da mulher, a falta de representatividade política, as disparidades salariais, dentre tantos outros exemplos que fazem indagar se há ou não outros fatores, além da dominação patriarcal, que influenciam no processo de desigualdade.

Foucault (1999a, p. 93-97) entende que a ordem da sexualidade não deve ser encarada sob a ótica de quem tem o poder em detrimento de quem é privado dele, mas sim sob o viés de mecanismos de controles sociais consubstanciados em articulações estratégico-políticas. Um bom exemplo seria o discurso religioso, pois se o cristianismo antigo nos fez detestar o corpo em dado momento, em outros se dedicou a fazer-nos amá-lo no seio da família e da cientificidade, levando-nos a uma monarquia do sexo, "a ponto de votar-nos à tarefa infinita de forçar seu segredo 
e de extorquir a essa sombra as confissões mais verdadeiras" (FOUCALT, 1999a, p. 149).

A complexa relação entre saber e poder, que visa traduzir uma suposta universalidade e verdade do conhecimento científico na medida em que descarta epistemologias que emergem das experiências sociais e culturais, visa a desqualificar os discursos não jurídicos, sujeitando-os.

Por saberes sujeitados, eu entendo igualmente toda uma série de saberes que estavam desqualificados como saberes não conceituais, como saberes insuficientemente elaborados: saberes ingênuos, saberes hierarquicamente inferiores, saberes abaixo do nível do conhecimento ou da cientificidade requeridos (FOUCAULT, 1999b, p. 12).

A fragilização do sexo e da mente, correspondentes ao padrão não socialmente aceito, evidencia um discurso hegemônico que objetiva transformar os sujeitos em corpos dóceis, aceitantes de sua "anormalidade" e, consequentemente, reprodutores da idealização de sua incapacidade de obtenção do mesmo amparo legal dado ao que é padronizado, determinando regimes de verdades que se pretendem absolutas (FOUCAULT, 1987, p. 119).

Quando se analisa grupos identitários vinculados às temáticas internacionalmente conhecidas de Direitos Humanos, como a temática LGBTHAIQ $+{ }^{4}$, verifica-se que o processo de invisibilidade e de subalternização é uma resultante histórica da dominação do "anormal" pelo "normal". A "anormalidade" reproduz desqualificações discursivas como forma de assujeitamento.

A insurreição dos saberes sujeitados traduz-se na libertação dos saberes históricos pela reatividade à hierarquização científica do conhecimento, isto é, trata-se de um empreendimento de insurreição dos saberes sujeitados e dos discursos de poder, de forma a torná-los "capazes de oposição e de luta contra a coerção de um discurso teórico unitário, formal e científico" (FOUCAULT, 1999b, p. 14).

Insurgir-se contra o entendimento de mulher como sexo - com a tríade vagina-feminino-mulher - é hoje uma estratégia para a afirmação de identidades individuais e coletivas. A micropolítica subjacente à insurreição dos saberes sujeitados, no que tange à temática LGBTHAIQ+, 
remete à compreensão de que a mulher transexual e a travesti devem ter acesso às medidas protetivas da Lei no 11.340/2006 (BRASIL, 2006).

De toda forma, seja pela posição feminista acerca do patriarcalismo que envolve o tema, seja pela acepção do biopoder nas articulações políticas, os mecanismos da sexualidade revelam desníveis na compreensão daquilo que difere do padrão vagina-feminino-mulher, pênis-masculino-homem.

\section{EXPRESSÃO DE GÊNERO E IDENTIDADE DE GÊNERO}

Em consonância à sistematização de John Money e Robert Stooler - que introduziram na medicina a separação entre os conceitos de sexo (biológico) e identidade de gênero (psicossocial) - o termo transexualismo, desbotado pela prática de evidenciar patologias psíquicas num discurso revelador de instrumentalização pela gestão da sexualidade, não reflete a realidade de mulheres transexuais e de homens trans (ZAMBRANO, 2011, p. 98).

A definição do que é gênero, contudo, não é uma tarefa trivial - já que o termo remonta a acepções linguísticas interessantes e controversas. É que dependendo de onde o sujeito é colocado, o objeto de análise pode ser deslocado. Para Judith Buttler (1990, p. 24):

[...] gender is not a noun, but neither is it a set of freefloating attributes, for we have seen that the substantive effect of gender is performatively produced and compelled by the regulatory practices of gender coherence. Hence, within the inherited discourse of metaphysics of substance, gender proves to be performative - that is, constituting the identity it is purported to be. In this sense, gender is always a doing, though not a doing by a subject who migth be said to preexist the deed [...] no gender identity behind the expressions of gender; that identity is permarmatively constituted by the very "expressioons" that are said to be its results. ${ }^{5}$

A identidade de gênero, então, deve ser considerada como o resultado das expressões de gênero. Compreendendo a transexualidade a travestilidade como identidades de gênero advindas das expressões de gênero tem-se, nos termos de Judith Buttler (1990, p. 181) que: 
Transexualidade, travestilidade, transgênero são expressões identitárias que revelam divergências com as normas de gênero uma vez que estas são fundadas no dimorfismos, na heterossexualidade e nas idealizações. As normas de gênero definirão o considerado "real", delimitando o campo no qual se pode conferir humanidade aos corpos.

Entende-se que a mulher transexual, ou transexual feminina, ou ainda Male to Female (Mtf) - é toda pessoa que reivindica o reconhecimento social e legal para o gênero feminino, conforme aduz Berenice Bento (2012). A travestilidade, aqui, não se distingue da transexualidade pelos critérios usualmente utilizados: politização da primeira, desejo por realizar a transgenitalização atinente à segunda; forma de se viver individualmente o gênero comum à ambas. Nos termos de Berenice Bento (2012, p. 76):

Se a diferença não está fundamentalmente na forma como se vive individualmente o gênero, pois no campo da subjetividade vamos encontrar uma gama de respostas que são articuladas como desdobramentos de vivências pessoais, tampouco se podem ancorar nas performances de gênero esta resposta, pois ambas as experiências identitárias negociam e transitam na ordem de gênero, sendo incorreto afirmar que uma está mais próxima da "mulher de verdade", pois a própria "mulher de verdade" carece de originalidade.

A existência ou não da cirurgia de transgenitalização não é empecilho ao entendimento do corpo e da mente como feminino, pois faz-se necessário compreender a dimensão da autodeterminação na titularidade do corpo que o compõe, bem como não é empecilho para compreensão de que estes corpos devem ter proteção jurídica. Para Capelo de Souza:

A natureza deste (corpo humano), enquanto bem juscivilisticamente tutelado, impõe ainda o relevo jurídico do poder natural de autodeterminação de cada homem sobre o seu próprio corpo. Pelo que, o titular do corpo tem poderes juridicamente reconhecidos em exclusividade [...] para dirigir e conformar o seu próprio corpo, para se sujeitar ou não a tratamentos e operações (SOUZA, 2011, p. 223).

Trata-se da percepção de que a mulher transexual e a travestilidade independem da realização da cirurgia de transgenitalização e da utili- 
zação do nome social para afirmação da identidade feminina. 0 que as torna mulheres são desdobramentos de vivências pessoais de autorreconhecimento e reconhecimento social. Estes desdobramentos devem, ao final, ser considerados elementares jurídicas para acesso às medidas protetivas da Lei Maria da Penha.

\section{A LEI MARIA DA PENHA E O DIREITO PENAL}

A Lei no 11.340, de 7 de agosto de 2006 (BRASIL, 2006) é fruto da consolidação dos Tratados internacionais da Convenção sobre Eliminação de Todas as Formas de Discriminação contra as Mulheres - que foi aprovada pela Assembleia Geral das Nações Unidas por meio da Resolução no 34/180, em 1979; da Convenção para Prevenir, Punir e Erradicar a Violência contra a Mulher; da Convenção de Belém do Pará (adotada em Belém do Pará/Brasil, em 9 de junho de 1994, no Vigésimo Quarto Período Ordinário de Sessões da Assembleia Geral), além de ser representativa da história daquela que lhe dá o nome.

Conforme se depreende de seu Art. 1ํㅡ, trata-se de uma lei eminentemente preventiva que, diferentemente da maior parte das legislações de mesma natureza, tem seu foco mais diretamente na vítima do que no agressor.

Não se nega, aqui, todavia, que apesar deste caráter preventivo, os aspectos processuais e agravantes nela previstas geram critérios mais enérgicos de punição e, sabe-se, que a crença no Direito Penal como meio para a insurreição dos saberes sujeitados é uma escolha falaciosa, na medida em que não gera a promoção de direitos, mas a manipulação de direitos subjetivos para criação de mecanismos de controle social.

É cediço, todavia, que a própria Dogmática Penal, os Direitos Humanos e a noção de garantismo penal, vinculadas aos ideais iluministas e liberais, são dotados de uma certa reversibilidade ideológica, como alerta Salo de Carvalho (2009). Nascem da romântica percepção da criação de um direito que limita a atuação do poder punitivo estatal e de fornecimento, à sociedade, de uma suposta segurança jurídica, mas tornam-se 
instrumentos utilizados para a criminalização primária (criação de novos tipos penais).

La legitimación del derecho penal como instrumento idóneo para la protección y la efectividad de los derechos sociales y trans-individuales deriva de la concepción romântica que le atribuye, como misión, la tutela de bienes jurídicos. Obsérvese en la dimensión justificativa de protección de los derechos humanos, la ampliación del rol de las conductas punibles y, consecuentemente, del horizonte de proyección de la punición. Se verifica, dentro de la transformación del modelo jurídico-penal liberal, la primera expresión de reversibilidad ideológica. ${ }^{6}$ (CARVALHO, 2009, p. 152).

Sem aprofundarmos nesta questão, e considerando que a Lei $\mathrm{n}^{0}$ 11.340/2006 (BRASIL, 2006) está posta e não cria novos tipos penais. Considerando ainda que há uma série, não encontrada em outras leis, de programas de readaptação voltados para o(a) agressor(a); considerando que são notórios os elevados índices de mortalidade das pessoas transexuais pela cultura de um machismo endêmico na sociedade brasileira; considerando também que desde a vigência da Lei houve redução dos índices de violência contra a mulher, não faz sentido o argumento de que a percepção da mulher transexual e da travesti como sujeitos passivos das condutas de violência seja um fomento ao alargamento do poder punitivo estatal.

É possível argumentar, no que tange a este aspecto, que o Art. 1ํㅡㅁ da Lei 11.340/2006 (BRASIL, 2006) limita a possibilidade de afirmação identitária das transexuais e das travestis, vez que está calcado numa simbologia sexual sinalizadora de parâmetros anatômicos, genéticos e morfológicos. Todavia, em contrapartida, o Art. 5o da mesma Lei delimita que a configuração da violência doméstica e familiar contra a mulher é pautada em ações ou omissões baseadas no gênero.

Evidenciar que se trata de uma ação ou omissão baseada no gênero significa que as condutas são cometidas em razão da condição de ser mulher. Alice Bianchini traduz o escopo da abrangência da Lei:

Toda violência de gênero é uma violência cometida contra a mulher, mas o inverso não é verdadeiro. Caso concreto: mulher é baleada por seu companheiro. Motivo: ela iria delatá-lo à polícia. Não se aplica a Lei Maria da 
Penha, pois não há uma questão de gênero. 0 que é, então, violência de gênero? [...] A violência de gênero envolve uma determinação social dos papéis masculino e feminino (BIANCHINI, 2016, p. 29).

As características principais da violência de gênero, nos termos de Alice Bianchini, indicam que:

a) Ela decorre de uma relação de poder de dominação do homem e de submissão da mulher;

b) Esta relação de poder advém dos papéis impostos às mulheres e aos homens, reforçados pela ideologia patriarcal, os quais induzem relações violentas entre os sexos, já que calcados em uma hierarquia de poder;

c) A violência perpassa a relação pessoal entre homem e mulher, podendo ser encontrada também nas instituições, nas estruturas, nas práticas cotidianas, nos rituais, ou seja, em tudo que constitui as relações sociais;

d) A relação afetivo-conjugal, a proximidade entre vítima e agressor (relação doméstica, familiar ou íntima de afeto) e a habitualidade das situações de violência tornam as mulheres ainda mais vulneráveis dentro do sistema de desigualdades de gênero, quando comparado a outros sistemas de desigualdades (classe, geração, etnia) (BIANCHINI, 2016, p. 31).

A problemática, todavia, é que o papel de submissão da mulher também é reproduzido pela mulher transexual e pela travesti e, nestes termos, não deve haver restrição na proteção. Posições isoladas dentro da jurisprudência apontam para este entendimento, tais como a proferida pela juíza Ana Cláudia Veloso Magalhães no Processo 201.103.873.908, do TJGO. Algumas posições jurisprudenciais que entendem pela aplicação das medidas protetivas da Lei Maria da Penha às mulheres transexuais (abarcando as intersex) e travestis acabam, deterministicamente, colocando como condição à aplicação, a regularização do registro civil por meio da adoção formal do nome social ou à cirurgia de transgenitalização.

CONFLITO NEGATIVO DE COMPETÊNCIA. VIOLÊNCIA DOMÉSTICA E FAMILIAR. HOMOLOGAÇÃO DE AUTO DE PRISÃO EM FLAGRANTE. AGRESSÕES PRATICADAS PELO COMPANHEIRO CONTRA PESSOA CIVILMENTE IDENTIFICADA COMO SENDO DO SEXO MASCULINO. VÍTIMA SUBMETIDA À CIRURGIA DE ADEQUAÇÃO DE SEXO POR SER HERMAFRODITA. ADOÇÃO DO SEXO FEMININO. PRESENÇA DE ÓRGÃOS REPRODUTORES FEMININOS QUE LHE CONFEREM A CONDIÇÃO DE MULHER. RETIFICAÇÃO DO 
REGISTRO CIVIL JÁ REQUERIDA JUDICIALMENTE. POSSIBILIDADE DE APLICAÇÃO, NO CASO CONCRETO, DA LEI N. 11.340/06. COMPETÊNCIA DO JUÍZO SUSCITANTE. CONFLITO IMPROCEDENTE. (TJ-SC - CJ: 64616 SC 2009.006461-6, Relator: Roberto Lucas Pacheco, Data de Julgamento: 14/08/2009, Terceira Câmara Criminal, Data de Publicação: Conflito de Jurisdição n. , da Capital)

O posicionamento da Ordem dos Advogados do Brasil/Conselho Federal, referente à questão está disposto em Nota Técnica sobre a aplicabilidade da Lei Maria da Penha à Violência Doméstica Contra Transexuais e Travestis, emitido pelo Conselho Especial de Diversidade Sexual, que preceitua:

Transexuais e travestis se caracterizam pelo pertencimento a um gênero diverso daquele apresentado pelo fenótipo de seu corpo. Tanto quem anatômica e legalmente seja um homem, identificado no gênero feminino, como quem, anatomicamente seja uma mulher, se identifique como do gênero masculino. [...] A lei Maria da Penha não cria qualquer restrição às transexuais e travestis, tampouco exige prévia retificação do registro civil ou cirurgia de adequação de sexo, e onde a lei não restringe, não cabe ao intérprete fazê-lo. Estabelecida a proteção da mulher como gênero, e não como sexo, mostra-se plenamente aplicável à violência doméstica praticada contra transexuais e travestis do sexo feminino (CEDS - OAB, 2014, p. 2).

Evidente que tal posicionamento poderia suscitar uma flexibilização da legalidade estrita, pedra angular de todo Direito Penal que aspire à segurança jurídica, proibindo a retroatividade da lei penal, a criação de crimes e penas pelo costume, o emprego de analogias para criar crimes, fundamentar ou agravar penas e a incriminação vaga e indeterminada (BATISTA, 2001, p. 68-82), e que a tipicidade estaria ausente, entendendo-se esta como adequação do fato ao modelo previsto no tipo (PRADO, 2012, p. 426). Neste sentido, aponta a argumentação do Ministério Público da União, vencida no Acórdão 1089057:

PENAL E PROCESSUAL PENAL. RECURSO DO MINISTÉRIO PÚBLICO CONTRA DECISÃO DO JUIZADO DE VIOLÊNCIA DOMÉSTICA. DECLINAÇÃO DA COMPETÊNCIA PARA VARA CRIMINAL COMUM. INADMISSÃO DA TUTELA DA LEI MARIA DA PENHA. AGRESSÃO DE TRANSEXUAL FEMININO NÃO SUBMETIDA A CIRURGIA DE REDESIGNAÇÃO SEXUAL (CRS). PENDÊNCIA 
DE RESOLUÇÃO DE AÇÃO CÍVEL PARA RETIFICAÇÃO DE PRENOME NO REGISTRO PÚBLICO. IRRELEVÂNCIA. CONCEITO EXTENSIVO DE VIOLÊNCIA BASEADA NO GÊNERO FEMININO. DECISÃO REFORMADA. 1. 0 Ministério Público recorre contra decisão de primeiro grau que deferiu medidas protetivas de urgência em favor de transexual mulher agredida pelo companheiro, mas declinou da competência para a Vara Criminal Comum, por entender ser inaplicável a Lei Maria da Penha porque não houve alteração do patronímico averbada no registro civil. 2. 0 gênero feminino decorre da liberdade de autodeterminação individual, sendo apresentado socialmente pelo nome que adota, pela forma como se comporta, se veste e se identifica como pessoa. A alteração do registro de identidade ou a cirurgia de transgenitalização são apenas opções disponíveis para que exerça de forma plena e sem constrangimentos essa liberdade de escolha. Não se trata de condicionantes para que seja considerada mulher. 3 . Não há analogia in malam partem ao se considerar mulher a vítima transexual feminina, considerando que o gênero é um construto primordialmente social e não apenas biológico. Identificando-se e sendo identificada como mulher, a vítima passa a carregar consigo estereótipos seculares de submissão e vulnerabilidade, os quais sobressaem no relacionamento com seu agressor e justificam a aplicação da Lei Maria da Penha à hipótese. 4. Recurso provido, determinando-se prosseguimento do feito no Juizado de Violência Doméstica e Familiar contra a Mulher, com aplicação da Lei Maria da Penha. (Acórdão 1089057, Relator Des. GEORGE LOPES, $1^{\mathrm{a}}$ Turma Criminal, data de julgamento: 5/4/2018, publicado no DJe: 20/4/2018, grifo nosso).

Antes de se expor a motivação pela qual compreende-se que estes princípios não são considerados ofendidos pelo autorreconhecimento e pelo reconhecimento social de gênero, vale ressaltar que o Direito, como um todo, existe para proteção do ser humano e deve, portanto, voltar-se a este ideal constitutivo antes de delimitar a aplicação de uma legislação.

No âmbito das normas internacionais de proteção aos Direitos Humanos e da Constituição da República Federativa do Brasil, é hermeneuticamente adequado defender a percepção da mulher transexual e da travesti como mulheres. A dificuldade desta compreensão decorre, na verdade, de um ultrapassado e obsoleto padrão hermenêutico, reprodutor de um saber-poder hegemônico, heteronormativo e biopolítico, que insiste em utilizar princípios constitucionais como meramente valorativos, relativizando a força normativa da igualdade, da liberdade, do direito à 
sexualidade e ao próprio corpo, todos corolários do princípio da dignidade da pessoa humana.

Por trás deles [dos direitos humanos e fundamentais], encontram-se representações axiológicas de dignidade, liberdade e igualdade de todos os homens. Mas, a partir do momento em que uma Constituição os tenha positivado em seu texto, tornam-se direito vigente. Quem deseja rotulá-los como "valores", paradoxalmente os desvaloriza (MÜLLËR, 2007, p. 160-161).

A não observância, como direito vigente, de todos estes princípios implica a aceitação de uma constitucionalização álibi, em que o próprio texto constitucional (constituinte e reformador) apresenta-se:

[...] como álibi para os legisladores constitucionais e governantes (em sentido amplo), [...] e como adiamento retórico da realização do modelo constitucional para um futuro remoto como se isso fosse possível sem transformações radicais nas relações de poder e na estrutura social (NEVES, 1994, p. 95).

Considerando-se os princípios constitucionais como normas juridicamente válidas, passa-se ao enfrentamento da possível flexibilização dos princípios penais, ao se considerar as mulheres transexuais e as travestis como sujeitas passivas para fins de acesso às medidas protetivas da Lei Maria da Penha. É certo que tanto estas quanto aquelas são consideradas normas de observância obrigatória. Isto é, não se tratam de princípios meramente orientadores:

Se há desconforto na doutrina tradicional, a ponto de se chegar a considerá-los meramente orientadores - por sua aplicação de modo absoluto consistir em violação cotidiana - este desconforto advém de um defeito na realização do próprio Estado de Direito (ZAFFARONI, 2006, p. 200).

Neste ponto, enfrenta-se o princípio da legalidade estrita ou da reserva legal. A legalidade estrita é derivativa do princípio da legalidade - divulgada pela fórmula "nullum crimen nulla poena sine lege" - e, segundo Nilo Batista (2001): 
[...] surge historicamente com a revolução burguesa e exprime, em nosso campo, o mais importante estágio do movimento então ocorrido na direção da positividade jurídica e da publicização da reação penal. Por um lado, resposta pendular aos abusos do absolutismo e, por outro, afirmação da nova ordem, o princípio da legalidade a um só tempo garantia o indivíduo perante o poder estatal e demarcava este mesmo poder como o espaço exclusivo da coerção penal. Sua significação e alcance políticos transcendem o condicionamento histórico que o produziu, e o princípio da legalidade constitui a chave mestra de qualquer sistema penal que se pretenda racional e justo" (BATISTA, 2007, p. 65).

O principal aspecto deste princípio é a positivação, ou seja, sua função constitutiva. Considerando-se as bases edificantes do princípio da legalidade estrita, ainda segundo Batista (2001) - proibir a retroatividade da lei; proibir a criação de crimes e penas pelo costume; proibir o emprego de analogia para criar crimes, fundamentar ou agravar penas; proibir incriminações vagas e indeterminadas - percebe-se que a identificação da transexual e da travesti às mulheres, para acesso às medidas protetivas da Lei Maria da Penha, poderia afrontar a proibição de analogias para o agravamento das penas, vez que todas as condutas de violência previstas na Lei, se cometidas em razão da condição de ser mulher, agravam as penas ou conduzem a aspectos processuais mais gravosos.

A analogia é um recurso interpretativo, um procedimento em que se passa de uma enunciação singular para outra singular, inferindo-se a segunda em virtude de semelhança com a primeira:

\section{(1) M É P \\ (2) S é semelhante a $M$ \\ (3) S é P}

No presente caso, ter-se-ia, na proposição 1, que a mulher é protegida pela lei. Na proposição 2, que a mulher transexual e a travesti seriam semelhantes à mulher. Na proposição 3 , ter-se-ia que a mulher transexual e a travesti seriam, então, protegidas pela Lei, visualizando-se uma impossibilidade destas serem consideradas sujeitas passivas da Lei Maria da Penha, vez que a analogia redundaria em penas mais gravosas para o autor. Assente-se que, este argumento - analogia in malam partem 
- é o mais recorrentemente utilizado para inviabilizar a aplicação das medidas protetivas da Lei Maria da Penha às mulheres transexuais e às travestis, haja vista ser um instituto penal que deve ser considerado de interpretação eminentemente restrita.

Sustenta-se, todavia, que a mulher transexual e a travesti não são semelhantes à mulher. São, conforme os aspectos identitários e de reconhecimento social, mulheres. Se não há um conceito normativo indicativo do que seja ser mulher, não há que se falar que a legalidade estrita foi atacada. Não se estaria, assim, criando-se analogias, mas mudando-se a compreensão do que é ser (tornar-se) mulher. A não afronta ao princípio da reserva legal está, justamente, no fato de que a mulher transexual e a travesti encontram-se dispostas na proposição 1, e não na semelhança com o ser feminino.

Quanto à tipicidade, nos termos de Zaffaroni (2006), tem-se que se faz necessário analisar não só a previsibilidade legal (tipicidade legal), mas a íntima correlação desta conduta com a antinormatividade (tipicidade material). A conduta tem de ser, além de taxativa e claramente prevista, contrária ao ordenamento jurídico em geral.

Como se destacou acima, a Lei no 11.340/2006 (BRASIL, 2006) não traz a criação de nenhum novo tipo penal, mas apenas agravantes e aspectos processuais mais gravosos. As agravantes trazidas, que alteram o Código Penal brasileiro criando alíneas em artigos preexistentes, corroboram o ordenamento jurídico como um todo integralmente considerado. Isto porque possibilitam a realizabilidade social dos princípios constitucionalmente previstos. Se no aspecto da tipicidade legal não há inovações, no aspecto da tipicidade conglobante prioriza-se os direitos e garantias fundamentais, em atenção à efetivação desses mesmos direitos humanos e fundamentais. 


\section{CONCLUSÃO}

Aspectos identitários de autorreconhecimento e reconhecimento social de gênero devem ser considerados suficientes para a delimitação do que é ser (tornar-se) mulher e, consequentemente, para o acesso às medidas protetivas da Lei 11.340/2006 (BRASIL, 2006) - popularmente conhecida como Lei Maria da Penha.

A percepção de que mulheres transexuais e travestis - independentemente de cirurgia de transgenitalização e de adoção do uso do nome civil - devem ser sujeitas passivas das condutas de violência previstas na Lei Maria da Penha advém do fato de que ambas vivenciam papéis de gênero feminino e que, nestes termos, devem ser consideradas como se sentem, como se reconhecem ou como socialmente são reconhecidas: mulheres.

A determinação do que é ser mulher não decorre de um conceito normativo. Por tal via, a compreensão de gênero - que ultrapassa o padrão da tríade vagina-feminino-mulher - se mostra atenta ao eterno construir-se do ser feminino, à observância obrigatória dos princípios constitucionais para a promoção de uma realizabilidade social. Tem-se, por tal perspectiva, a insurreição de seres e saberes historicamente sujeitados, subjugados inclusive e fundamentalmente pelo próprio Direito. Possibilita-se assim uma reversibilidade nas relações microfísicas de saber-poder.

Mas, é preciso perceber a função ambivalente - normalizadora e emancipatória - do Direito neste processo. No âmbito da analítica do poder foucaultiano (FOUCAULT, 2004), as relações de poder se desdobram em estratégias libertárias e estratégias de dominação. A função tradicional do Direito neste panorama se materializou nas estratégias de dominação. E é bem isso o que se percebe na rejeição institucional da identificação das transexuais e das travestis à mulher. Contudo, a adoção de ferramentas hermenêuticas aptas a manter o Direito sensível às necessidades e demandas da sociedade, em toda a sua hipercomplexidade, pode alterar a função hegemônica do próprio Direito que, neste cenário, pode superar a função histórica de dispositivo opressor de normalização, assumindo a função de dispositivo emancipatório de subjetivação. 
As diretrizes do Direito Internacional dos Direitos Humanos, do constitucionalismo contemporâneo, da dogmática penal e do garantismo penal, incursos numa reversibilidade ideológica flagrante, não devem utilizar-se, sem análise sistêmica do próprio Direito e das relações de poder que o sustentam, do discurso de fomento à cultura do punitivismo para negar o acesso das mulheres transexuais e das travestis à proteção dada pela Lei 11.340/2006, inclusive por tratar-se de um grupo temático de Direitos Humanos marcado por altíssimos índices de mortalidade violenta na sociedade brasileira atual.

Para que o Direito brasileiro contemporâneo possa contribuir para a afirmação da identidade de subjetividades individuais e coletivas historicamente marginalizadas e excluídas e, especificamente, para que este Direito se afirme como um dispositivo emancipatório de subjetivação das transexuais e das travestis, no âmbito da violência doméstico-familiar, não é necessário reinventar o próprio Direito, muito menos subverter o princípio da legalidade estrita.

No caso da dogmática penal, a partir da Lei em análise, verifica-se que não há alteração do bem jurídico tutelado, nem tampouco a construção de criminalizações primárias, isto é, a criação de novos tipos penais, ou ainda a construção ou o uso indevido de analogias. Isso porque as agravantes previstas na Lei não se criam a partir da semelhança entre mulheres travestis e transexuais com mulheres, mas decorrem do reconhecimento de que ambas encontram-se na mesma esfera de proteção. A reserva legal e a tipicidade, neste quadro, permanecem de observância obrigatória e rigorosamente intactas.

\section{Notas}

1 Cirurgia de transgenitalização: É uma das etapas do processo transexualizador. Também conhecida como mudança de sexo, redesignação sexual (SRS), readequação sexual, cirurgia corretiva. Para os transexuais masculinos, consistem na histerectomia, mastectomia e na construção de pênis. Na histerectomia retira-se o aparelho reprodutor e na mastectomia, os seios. De uma forma geral, os homens transexuais fazem a opção pelas duas cirurgias, a histerectomia e a mastectomia. Nas transexuais femininas, a cirurgia destina-se à produção da vagina e de plásticas para produção dos pequenos e grandes lábios (BENTO, 2012, p.187).

2 Nome social é aquele pelo qual travestis e transexuais se reconhecem, bem como são identificados por sua comunidade e em seu meio social (Art 1ํ, § 1ํㅡ, Decreto no 51.180 de 14 de janeiro de 2010, prefeitura de São Paulo). 
3 A expressão transgênero é uma expressão lato sensu que visa traduzir a transexualidade (mulher transexual e homem trans), travestilidade e os intersex. Os intersex - popularmente conhecidos como hermafroditas - quando adotam a identidade de gênero feminina também devem ter acesso às medidas protetivas da Lei, independentemente da cirurgia de transgenitalização. As medidas protetivas da Lei Maria da Penha devem abarcar, portanto, as expressões de gênero e identidades de gêneros da feminilidade: mulheres transexuais, intersex que se vivenciam papéis de gênero feminino, travestis e mulheres cisgêneras (independentemente de suas orientações afetivas).

4 A terminologia para designar o grupo temático LGBT muda a partir da perspectiva e referência adotada: Academia, Movimentos Sociais, Governo. A sigla mais comumente utilizada é a LGBT - sendo a sigla predominantemente adotada no meio governamental para referenciamento de políticas públicas vinculadas a Direitos Humanos. LGBTI é a sigla empregada por órgãos internacionais como a $\mathrm{ONU}$ e a Anistia Internacional. Em determinados segmentos, principalmente vinculados à Academia, têm-se ganhado força a modificação da sigla para incluir além de orientação sexual, a diversidade de gênero, os assexuais, os hijra, os intersex, além da perspectiva teórica e política dos Estudos Queer - motivo pelo qual, adotou-se, aqui a sigla LGBTHAIQ+. Preferiu-se, aqui, a adoção desta por ser uma nomenclatura includente - evitando deixar de lado quaisquer tipos de compreensões.

5 Tradução: [...] o gênero não é um substantivo, mas tampouco é um conjunto de atributos flutuantes, pois vimos que seu efeito substantivo é performativamente produzido e imposto pelas práticas reguladoras da coerência de gênero. Consequentemente, o gênero mostra ser performativo no interior do discurso herdado da metafísica da substância - isto é, constituinte da identidade que supostamente é. Nesse sentido, o gênero é sempre um feito, ainda que não seja obra de um sujeito tido como preexistente à obra [...] não há identidade de gênero por trás das expressões do gênero, essa identidade é performativamente constituída, pelas próprias "expressões" tidas como seus resultados.

6 Tradução: A legitimação do direito penal como instrumento idôneo para a proteção e a efetividade dos direitos sociais e transindividuais deriva da concepção romântica que lhe é atribuída, como missão, a tutela dos bens jurídicos. Nota-se a dimensão da justificativa de proteção dos direitos humanos na ampliação do rol de condutas proibidas e, consequentemente, do horizonte de projeção da punição. Verifica-se, dentro da transformação do modelo jurídico penal liberal, a primeira expressão de reversibilidade ideológica.

\section{REFERÊNCIAS}

BATISTA, Nilo. Introdução crítica ao direito penal brasileiro. 11. ed. Rio de Janeiro: Editora Revan, 2007. 136 p.

BEAUVOIR, Simone de. 0 segundo sexo, a experiência vivida. Tradução de Sérgio Milliet. São Paulo: Difusão Européia do Livro, 1967. v. 2. 500 p.

BENTO, Berenice Alves de Melo. 0 que é transexualidade. 2. ed. São Paulo: Brasiliense, 2012. 222 p.

BIANCHINI, Alice. Lei Maria da Penha: Lei n. 11340/2006: aspectos assistenciais, protetivos e criminais da violência de gênero. 3 ed. São Paulo: Saraiva, 2016. 247 p. 
BRASIL. Lei no 11340, de 7 de Agosto de 2006. Cria mecanismos para coibir a violência doméstica e familiar contra a mulher, nos termos do § 80 do art. 226 da Constituição Federal, da Convenção sobre a Eliminação de Todas as Formas de Discriminação contra as Mulheres e da Convenção Interamericana para Prevenir, Punir e Erradicar a Violência contra a Mulher; dispõe sobre a criação dos Juizados de Violência Doméstica e Familiar contra a Mulher; altera o Código de Processo Penal, o Código Penal e a Lei de Execução Penal; e dá outras providências. Brasília: Senado, 2006. Disponível em: < http://www. planalto.gov.br/ccivil_03/_Ato2004-2006/2006/Lei/L11340.htm>. Acesso em: 1 jul. 2016.

BUTTLER, Judith P. Gender trouble: feminism and the subversion of identity. United States of America: Routledge, Chapman \& Hall, Inc. 1990.172 p.

\section{CARVALHO, Salo de. Criminología, garantismo y teoría critica de los} derechos humanos: Ensayo sobre el ejercício de los poderes punitivos. Revista de Derechos Humanos y Estudios Sociales, Sevillha, p. 149-177, 2009.

CEDS-OAB. Comissão Especial da Diversidade Sexual/ Conselho Federal da $\mathrm{OAB}$. Nota técnica sobre a aplicabilidade da Lei Maria da Penha à violência doméstica contra transexuais e travestis. 2014.

FOUCAUT, Michel. Em defesa da sociedade: curso no College de France (1975-1976). Publicado em 1999b. Tradução de Maria Ermantina Galvão. São Paulo: Martins Fontes, 2005, 382 p.

. História da sexualidade I: a vontade de saber. Rio de Janeiro: Edições Graal, 1999a. 151 p.

. Vigiar e punir. Tradução de Raquel Ramalhete. 20. ed. Petrópolis: Vozes, 1987. 288 p.

. Ética, sexualidade, política. Organização e seleção de textos Manoel Barros da Motta. Tradução Elisa Monteiro e Inês Autran Barbosa. Rio de Janeiro: Forense Universitária, 2004. 322p. (Ditos e escritos; V).

O sujeito e o poder, pp. 231-249. In: RABINOW, Paul; DREYFUS, Hubert. Michel Foucault, uma trajetória filosófica: (para além do estruturalismo e da hermenêutica). Rio de Janeiro: Forense Universitária, 1995. 299 p. 
MARANHÃO, Odon Ramos. Curso básico de medicina legal. 7 ed. São Paulo: Malheiros, 1995. 387 p.

MIGUEL, Luís Felipe. BIROLI. Flávia. Feminismo e política: uma introdução. 1. Ed. São Paulo: Boitempo, 2014. 164 p.

MÜLLËR, Friedrich. 0 novo paradigma do direito: introdução à teoria e metódica estruturantes do direito. São Paulo: Editora Revista dos Tribunais, 2007. $272 \mathrm{p}$.

NEVES, Marcelo. A constitucionalização simbólica. São Paulo: Editora Acadêmica, 1994.191 p.

PRADO, Luiz Regis. Curso de direito penal brasileiro. Vol. 1: parte geral, arts 1o a 120. 11 ed. São Paulo: Editora Revista dos Tribunais, 2011. 873 p.

SAFFIOTI, Heleieth. A mulher na sociedade de classes: mito e realidade. 3 ed. São Paulo: Expressão Popular, 2013. 404 p.

SAO PAULO (SP). Decreto no $\mathbf{5 1 . 1 8 0}$ de 14 de janeiro de 2010. Dispõe sobre a inclusão e uso do nome social de pessoas travestis e transexuais nos registros municipais relativos a serviços públicos prestados no âmbito da Administração Direta e Indireta, conforme especifica. Poder Executivo Municipal, São Paulo, SP, 14 jan. 2010.

SOUZA, Rabindranath V.A. Capelo de. 0 direito geral da personalidade. Coimbra: Coimbra Editora. 2011. 708 p.

ZAFFARONI, Eugenio Raúl Eet al. Direito penal brasileiro: primeiro volume: teoria geral do Direito Penal. 3 ed. Rio de Janeiro: Revan, 2006. 658 p.

ZAMBRANO, Elizabeth. Transexuais: identidade e cidadania in Diversidade sexual e homofobia no Brasil. São Paulo: Editora Função Perseu Abramo, 2011. $251 \mathrm{p}$.

Artigo recebido em: 21-5-2017

Aprovado em: 12-11-2018 


\section{Bárbara Amelize Costa}

Mestranda e bolsista da CAPES no Programa de Pós-Graduação em Direito da Pontifícia Universidade Católica de Minas Gerais (PUCMINAS); especialista em Tecnologias em Educação pela Pontifícia Universidade Católica do Rio de Janeiro (PUC-RIO); coordenadora da Central de Recebimento, Monitoramento e Avaliação em Direitos Humanos (CENTRAL). E-mail: barbaraamelize@gmail.com

\section{Adalberto Antonio Batista Arcelo}

Doutor mestre em Direito pela Universidade Federal de Minas Gerais. É professor da Pontifícia Universidade Católica de Minas Gerais e professor do Curso de Direito da Faculdade Arquidiocesana de Curvelo - MG. E-mail: adalbertoarcelo@ gmail.com

Pontifícia Universidade Católica de Minas Gerais. Programa de Pós-Graduação em Direito

Avenida 31 de março, no 1020 - Prédio 93 - Dom Cabral - Belo Horizonte/MG - CEP: 30535000 
